\title{
MOTIVATION AS REALISATION OF NEEDS AND INTERESTS
}

In the study, the authors analyse all the factors of human motivation which lead to a concrete act of a subject. It is not only about mechanical analysis of the components of motivation structure, but also about reciprocal dynamic links and connections. It deals with the relation between motives, needs and interests as a multilateral continual process.

\section{Introduction}

Human activities imply complex systemic creations. When characterising the structure of an activity, its elements such as needs, motives and interests are analysed isolated, or more precisely in their mechanical connection. In the following work, we will try to clarify the dialectic links between these elements, the way they interlock with each other and create the result of an activity. This is presented as a multilateral and continual process which represents a unity of contradictions between social and individual, material and idealistic, objective and subjective. This unity of contradictions and opposition subsumes the transformation of these discrepancies into one motive force of a creative subject - into the motivation as such.

\section{Motivation and Motive}

The term motivation originates from the Latin word moveo, are and it means move, stir (substantive: motio, onis - motion, passion). We can come across several definitions of this notion in specialised literature. According to Berelson and Steiner it is "an inner state of human soul, which activates a person or puts him into motion." Provazník considers the motivation as "a set of factors representing the inner moving forces of human activities, forces which guide our cognition, experience and action." [1] The basic category which motivation deals with is a motive (stimulus). Motives express psychological causations or reasons of behaviour and give the behaviour a psychological sense. We can apprehend them as specific inner conditions. [2]

The process of motivation is complex and has a multidimensional character. It can be assumed that motivation is a subjective expression of dialectic effects of externally and internally arising needs of action. In the motives of action, it is necessary to see the psychological phenomenon, which is determined by the sum of social conditions and which becomes a moving force and an imme- diate cause of action and activities of a subject. There are three basic factors which concur at the formation of a motive. They are:

- Actual needs,

- Living conditions,

- Inner position of a subject.

This reciprocal and integral concurrence is objectively necessary as each of these three factors is determined by the way of life in a society. However, each has also its roots outside the subject, though each originates inside the subject as it is subjectively reflected in the process which runs in dependence on determination by social conditions. These three factors are elements of the way of life in the society in which they originate. In its forms of occurrence, the motive is socio-structurally differentiated.

Quality, content and power of motives, which originate in the situations of decision-making of the subject, are different according to affiliation to different social groups of society. This socio-structural aspect of motivation can be entitled as "social specificities of a person". We understand this mainly as a position of people in their social structure of society, socially important characteristics of groups which they belong to, and eventually individual particularities (age, education, personal qualities, marital status). The motives, as well as the needs, are always specific. It is necessary to view them in the context of material-spiritual life of the society, socio-structural differentiation and in the specific conditions of the situation of the subject's decision making. In case we investigate which of these factors is more primary, we come to the conclusion that it must be living conditions of the subject. They occur as past (when determining the inner position), present and anticipated. Here we use the argument of L. Séva who speaks about "a reality, which determines relationships". (When we use the notion "living conditions", we consider material-spiritual life of a society, which the living conditions directly result from). In case we would like to express the meaning of living conditions in this process metaphorically, we could compare them to the source of light and human

\footnotetext{
* Alfréd Prigl ${ }^{1}$, Henrieta Priglová $^{2}$, Bronislava Jakubíkováa

${ }^{1}$ Department of Pedagogy, Psychology and Social Science, Faculty of Science, University of Žilina, E-mail: alfred.prig@@fpv.utc.sk

${ }^{2}$ Department of Library and Information Science and Didactics of Informatics, Faculty of Science, University of Žilina, E-mail:

henrieta.priglova@fpv.utc.sk, bronislava.jakubikova@fpv.utc.sk
} 
characteristics to the lens in which the ray of light emerging form the source refract.

The forms of motives could be expressed by the terms as: instincts, values, emotions aspirations, interests, ideals, efforts, wishes, fears, inclinations, dislikes etc. However, their content is closely associated with the needs, which form their base. The need expresses the basic form of a motive, and that in terms of a certain shortage at the level of physical and social being. Accordingly, the aim of human behaviour is to reduce the needs. This reduction is considered in various forms of satisfaction (saturation, relax, relief after evading a danger, feeling of security, personal importance etc.). According to Leontiev "an object that can satisfy a need is not fixed in the need itself. By the time, the need is satisfied for the first time, it does not "know" its object; this must only be discovered. Only by this discovery, the need acquires its objectiveness and the known object gains a function of initiation and regulation of activities, whereby it becomes a motive." [3]

In the scope of methodology, it is not very helpful to mechanically analyse and formulate the content of motives. Nevertheless, we could roughly differentiate motives conditioned biologically and socially on one side and materially and ideologically on the other side. From the methodological point of view, it is more important to describe motives and issues from the concrete needs which express the motives. We ponder: in a human as a subject and in the world as an object, in the process of the subject's individual and social being, the requirements of its actual needs regularly arise from this dialectic connection. These needs are fulfilled and saturated inside him. The saturated needs evoke new requirements or new orientation or extra activities which lead to the meeting of requirements. Yet, a whole range of new needs arises that are not in accordance with the requirements. The more developed personality, the richer the structure of need and the higher number of motives the richer their content. For the full understanding of the process of motivation, it is necessary to pay enough attention to the problem of the needs. Since the process of motivation is the most complex structural dynamism of human doing and activity.

\section{Needs}

The human needs are the basic drive and motivation power of each human act. Their origin is in biological conditions of a life of organism, in which the determination of human behaviour plastically originates. Thereby, the needs create an important part, dynamic core of the structure of human personality and at the same time they create a subjective background of motivational processes. A person is forced to cope with outer and inner changes which create tension. $\mathrm{He} /$ she tries to adjust and eliminate this state of tension which continually rises. The reasons of this tension are either in the excess or shortage of a substance or energy of inner and outer environment. This is the way how the motivation comes into existence.

The human needs are concurrently a subjective base of motivation. By the means of physiological mechanisms they influence the energy charge necessary for a development of the activity which leads backwards to their satisfaction. The size, intensity and power of energy charge is directly dependent on the fastidiousness of the activity and on the extent to which the need linked to an activity is important to the subject. Substantial and significant fact is that the needs also determine the interests of a person. Individual character and content of the needs has a short-term or a long-term influence on person's sensibility and perception of certain stimulus, activity and situation and their evaluation. To a great extent it depends on which of the needs prevails and becomes dominant to the others as the needs can exclude one another but also concur together. Predominance of a certain need or group of needs is temporary and is a subject to change. Nevertheless, one of them can dominate for a longer time period and can become characteristic for a certain person. Activation, fixation and influence of a particular need can change mainly according to its satisfaction. Saturated needs get weaker, retreat to background to the other needs but after some time they can reappear and require more intensive saturation. It is also possible, that not only the saturated needs retreat to background but also the needs which were not satisfied for some objective reasons lose the intensity and become latent. Eventually, they can reappear and require saturation far more dynamic and vigorous.

Dynamics of scientific, technical, industrial and social development as a human product invades the stability and change human values and needs. The more demanding and differential the human values and needs are, the more complicated and varied the motivation is. Low degree of development of production forces was accompanied by simplification of the link between the needs and aims of an individual and the needs of a society. Naturally, this has also simplified the relation between the motivation and the needs of a human. At these circumstances, it was possible to manage the production forces development without distinctive differentiation and specific motivation. In the setting of apparent civilization and cultural development of the society and its economic growth, not only mass and variety of consumption and other factors of living standards become adequate, but also the increase of claims on saturation of increasing human needs. Awareness of this reality must stress the cognitive and focused activity issuing from the perfect knowledge of the optimization of human needs to create such conditions which would allow the cultivation of human needs and become a vital social norm of motivation.

Types of motives point out their specific content, i.e. a specific saturation which should be achieved. [2] Types of motivation can be classified in a following way:

- According to their origin:

1. Physiological motives which express the biological needs of organism such as need of food, motion, rest, etc.

2. Socio-psychogenic motives which express the needs of a human as a social being, such as need of action, support, competence, etc.

- According to the values: positive and negative

- According to the level of consciousness: conscious and unconscious 
The notion stimulus (from Latin word stimulus - spike, prick), on the contrary, denotes an external impulse to the encouragement or activation of motives. [1] Stimulus, in contrast to a motive, is an objective phenomenon and has either material or immaterial influence on a human form outside. This influence evokes certain reaction and its function is to reach certain desirable behaviour of a person. All the external considerations concurrently pass through the system of needs and value orientation and in consequence they become grounds of actions (motives). [4] As a final consequence, individual characters of a person determine the activity as a reaction to the external influences.

\section{Process of motivation}

Each socially important activity is complexly motivated. It is less probable that this kind of action is directed only by one motive or a few. We can sum up, that in each process of creation of a motive we have to take into account the other motives which have already been there and have conditioned its formation. We also need to consider the variety of motives which are in contradiction, i.e. rejected and updated as well. This process of motive formation cannot be always viewed as a fully conscious and intellectually managed approach of a subject. The motives which the subject considers are not always a complex of a whole variety, diversity and richness of motives which exist in its consciousness. Concerning the given situation certain motives can be pushed to the background by more preferred, stronger, more urgent motives.

We can assert that a motive is a psychological phenomenon which operates by means of its energizing and directing function immediately as a dynamizer of an action. It gives the activity a potential intensity and direction. Motive, as a part of individual consciousness, is a specific form of expression of social sense. It originates on the ground of actual needs and that leads it to the achievement of the aim. Motive becomes a mediator in objective causal context of the action in which the needs create a relation towards living conditions. World-view and value orientation of the subject, its abilities, talents, emotions and interests influence the story of this process and create a motive. Emotions have an inner function of signals. A peculiarity of emotions is their reflection of the relations between the motives and a success or possibility of

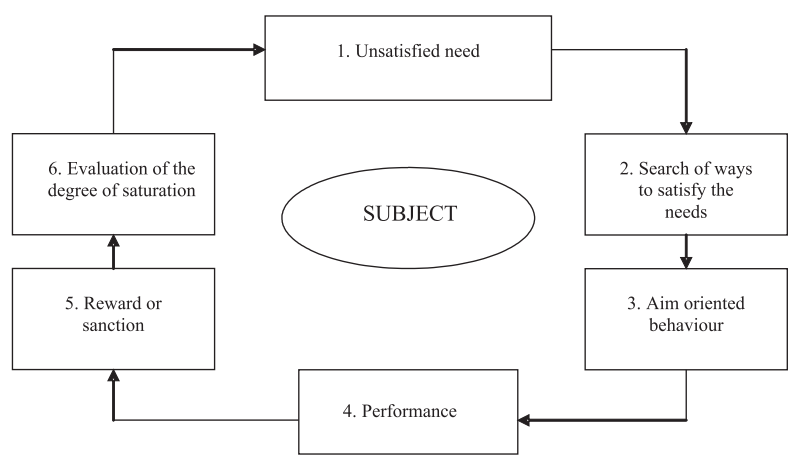

Fig. 1 Basic scheme of motivation [1] successful realisation of the activity of object which corresponds with the motive. Emotions rise immediately after the actualisation of a motive, and before the subject evaluates its action rationally. Emotions play a role of a positive or negative "sanctioning" in relation to the effects which are given by the motive. A person does not realize common motives which initiate his actions.

Not one, but a structure of more motives give the action a direction and intensity. It appears from the previous that the action leading to the saturation of needs is grounded on a group of motives. We call this combination of motives motivation. We understand the term of motivation not as a process of motivation but as a state of being motivated (state of readiness for an action). This quantitative aspect (sum of several motives) leads to a qualitative aspect to state of readiness and actualisation of the action. The process of motivation can be illustrated by the following scheme [1]:

A set or sum or motives is rarely deliberately and unitedly target oriented, or let us say the content of individual motives have often contradictory even antagonistic character. What is the cause that despite the ambiguous and contradictory process of motivation, the activity is unitedly target oriented? Motive in relation to a value has also a function of a selector. The result of this selection is, in our opinion, the interest. Interest is a selectively preferred motive which expresses an act of inner conviction - identified with its object. In relation to values, it chooses the value which is the most adequate to the conditions of a subject and which fully corresponds with the subject's value structure or with the objectively given situation.

\section{Interest}

Even if we define interest only as a specific type of motivation, in contrast to basal motive, it has these basic postulates:

- Focus (target),

- Conviction (identification with the object of interest),

- Awareness (of its objective condition and means of its realisation),

- Differentiation and hierarchy (ability to subordinate all the partial interests to the one central interest),

Accordingly, the interest is a constant, conscious and usually focused effort of a subject, leading to the reproduction and fulfilment of unsaturated needs. Interests project the need into selective preference of certain values, which are due to the acceptance of definite historical norm considered as a part of the existential optimum.

In contrast to the psychological conceptions of the interest, which characterise the interest as a subjective phenomenon of a consciousness, philosophy understands the interest as a subjectobject entity. The difference between the psychological and philosophical understanding of the interest is following: interest is objective. It is a basic component of the structure of a human activity which acts as a source of the activity so it would be able to mobilise 
and dynamise the action of people in case of contradiction with the object. It is not enough to say that the interest is objective. Interest which approves itself in a concrete activity, transforms objective into subjective. Thus, it is a subject-object component of the activity structure by the means of which the subject subordinates itself to the existence and development of social and economic systems. The laws of these systems are projected to the direction of the activities of the subject which gains them a concrete form of expression. The objectivity of the interest can be also seen in the fact that it has no objective content and direction and that it is determined by material level of social development and social relations. The subjectivity of the interest can be seen in the individual choice of interests by each subject who is determined by the resources of their realisation, own needs and culture, social and value orientation.

\section{Relation motive-interest}

The difference between a need and an interest is that a subject does not necessarily have to be aware of a need, yet an interest has always a cognitive objective content. It can be asserted that the interests originate at a relatively higher level of human development than the needs. In the relation need - interest we assume, that the interest can originate as a selectively preferred need with a higher involvement of a subject and with a higher rate of its activation. The need produces the interest when there are some obstacles with its saturation or the saturation is endangered for a shorter or longer period. Afterwards, the interest activates the whole action of the subject which leads to the realisation of the activities.

If we have priory dealt with the relation motive-interest than we can basically assert that the notion motive in relation to interest takes on a different meaning in philosophy than in psychology. Whereas in psychology, the interest is characterised as a resultant of motivational contradiction and as an objective phenomenon (focus) and motives subjective, form the philosophical point of view in a social interaction, the interest of an individual can become subjective (motive) towards objective, i.e. common social interest.

Our arguments are: the interest presents mainly the efforts of a subject to reach the set target in such activities which focus on this act. Still, this activity must be motivated. A person can act under the influence of a material interest in a dishonest way, but the motives of his/her actions could be perceived or explained as generous and noble to excuse his/her action in front of the others, social norms or even himself. This is the reason why we cannot judge the actions or even the real interests of people only according to motives alone. In the motivation sphere, the interest can be mirrored in a deformed, twisted sense, in an illusionary image. Quite often, people do not realize the real stimulation forces which make them react in one way and not the other; they cheat themselves by various mystifications and illusions about the reasons of their actions.

It appears from the previous that the realisation of the interest does not only depend on will-power characters of the subject and his abilities, but mainly on independence from other circumstances. Reciprocal relationship of social being, needs and interests is one of the basic mechanisms of the social movement.

Philosophers and sociologists who deal with the problem of interest are united in the evaluation of the conditioning of production-economic relations in a narrow sense and social relations in a broader sense. There were presented several theories about the essence of social interests, which can be divided roughly into three basic approaches:

- Reduction-sociological concept of interest generalises the psychological application of the interest. The essence of the social interest in this approach is comprised by awareness of a social content of various interests i.e. in the final consequence a field of social consciousness. This conception ignores an individual activity and specificity of each human need, his/her focus, individuality and uniqueness. It mechanically reduces social to individual without evaluation of dialectics of this relation and its interactions.

- Interest is understood as a unity of objective and subjective: objective state of subject and ideal dynamizing activating subjective powers i.e. wishes, efforts and motives of the activity. To these conceptions also belong the opinions according to which the interest means a conscious need.

- Interest relates to the objective side of the social life and is understood as an objective phenomenon or the reflection of the social reality. It is transformed into intra-individual side of human psyche which forms the base of subject-object interaction in a scheme subject - object - psyche. Hence, the interest does not come to existence because the subject is aware of it but because he/she is aware of its objective content.

Interest in connection with an individual, social group etc, forms a moment of an objective side of a social life of which correct or incorrect understanding is formed by subjective side of wishes, motives, impulses, in short - stimulus of focused practical activity. Not the interest itself but its realisation contains the moment of unity of objective and subjective. Accordingly, the interest is expressed in a form of stimulus inside the consciousness; this stimulus leads to activity, the activity changes or consolidates social relations which reproduce the interest on the outside. This is dialectics of subjective and objective in the realisation of the interest. On the grounds of the interests, social rules as permanent links between individual and social outline a general direction, content and form of interest at an adequate level of human activity. When the interest changes into a subjective side of the social process, it transforms the social rules into stimulus adjusting the tendencies of human social behaviour to necessary social norms which are bounded or approximated and codified by these requirements. According to our definition, the scheme of movement and development of the social connections and processes looks after this manner: interest - purposeful activity - interest.

We cannot talk about motivation as a common sum of several motives but about motivation as a specific unit. The reason is that motivation represents a qualitative aspect. This qualitative aspect 
in relation to the aim can be seen in two contrasting qualities which are:

- Promptness to fulfil the requirements,

- Refusal of the requirements.

This qualitative feature flows from the orienting components of motives which are inherent in motivation. Each quality of motivation expresses the content which defines the needs that were created by the previous motivation.

The content of motivation is a particularity of the relation of the personality towards social and natural environment, and it is possible to recognize it only form the analyses of the needs of the subject. Therefore, we can assume that:

- Motivation is an activating ground of an action in certain intensity, thus it takes an effect in "quantified power", whereby, the intensity flows form the activation components of motives inherent in their content.

- It links certain number of motives which make its structure. Its structure or hierarchy emerges from different strength of the effect of motives of the same quality.

The motivation does not only emerge directly from the variety of needs which are updated by the use of requirements, as these needs can be qualitatively different, considering the aim of the action.

\section{Attitude}

Let us set an example: If there is an actual need to achieve a material stimulation on one side and on the other side its achievement is linked with a risk, than the inner position of the subject, i.e. its system of values, makes the decision about the action and activity. From the intensity of the motivation emerges the strength of its effect on the will-power characteristics of the subject and also on its stability. The stronger motivation provokes a more stable motivation unless there is a change of an actual need. It could be said that by the saturation of needs or a change for different motives or motivation, the original motivation expires.

As we have asserted previously, motives are a dynamic power of social-creative activity of a person, we believed that the motivation gives the action a direction and intensity which quality has a structure and a certain extent. Let us consider what the content of the quality side of the motivation is. From the previous consideration that the socio-economic relations determine the creation of motives results that motivations which are created on a certain socio-economic ground have a character which is derived from the socio-economic-sociable relations. By the fact that a person changes his/her social relations and himself/herself, even his/her motivations in these relations change. From the quality of the way of creation emerges the content of needs, quality of living environment and also the change of human thinking. Despite the differences in motivations, which originate in different social groups in society and in their quality and contents, they have almost always the same character, only their structure is different.
We have already stated that the motives with their orientation function form the actual disposition of an action. This actual disposition can be generally called attitude. The attitude originates in the situation of decision-making and can be characterised as a state of readiness - promptness of a subject to solve the accrued situation. However, we need to differentiate the dynamic aspect of the attitude and the fixed attitude as a compact aspect. According to D. N. Usadze "attitude is a total state of a subject ... moment of its dynamic focus ... total focus in one direction on certain activity." [5]

In a wider sense, attitudes could be characterised as: particular systems which originate in a dialectic relation of penetration of social consciousness into the individual being and consciousness. Attitudes are practical objectification of the theoretical reflection of this relation. By the practical objectification, the subject takes a concrete stand towards a concrete reality and takes part in it, whether it is a theoretical (thinking of event) or practical part (acting of event). This participation can approve itself in a concrete action or evaluation of an action of oneself, social group, society, its ideology and actions. Considering the dynamics of its content, the attitude can not be static, inactive, isolated and encysted inwards to the individual psyche of the subject, but it always has to express a concrete relation - either positive or negative. The attitude is characterised exactly as an ability to react, express and act.

It appears from the previous that motivation as attitude depends on living conditions of a subject and its inner position. Both phenomena originate in a causal relation of the process of psychical preparation to act, which is focused on saturation of needs. Orienting and activating components of motives lead not only to quantitative and qualitative expression of motivation, but also to an adequate quality and strength of the attitude. Even though we have asserted that between the motivation and attitude there is a causal relation, we cannot absolutize it. The subject can occasionally have an attitude which is in conflict with its own interests etc. This discrepancy is a result of the complexity and versatility of the psychical processes of a subject. We have stated earlier that despite the differences of motivations which originate in different social groups they contain similarities in quality and content, and the character is almost always the same, the difference is only in their structure. If we ask a question what causes the unification of quality and content of motivation in different social groups then the unifying factor would be of interest.

The interest has already been characterised earlier as a selectively preferred and fixed, relatively constant motive in a subject. According to the content of this study, it would be possible to characterise it as: a link of several motivations which create an interest as selectively preferred motivation which extremely intensively dynamise the activity of the subject. However, the interest is a specific type of motivation. It is relatively autonomous or it has a dominant position in the hierarchy of motivation of the subject. Its importance for the subject and social movement was characterised by M. Vaross: "Realisation of interests does not only depend on will-power characters of a subject and its abilities, but also on objective autonomous circumstances. This dialectics of a social being, needs and interests is one of the basic mechanisms of a social movement..." 
[6] Pursuant to interests which are together with values a part of fixed attitudes (and arose requirement which needs a solution), attitudes reach a dynamic dimension and verge into a concrete action of the subject.

\section{Action and Activity}

Psychology studies an activity on the ground of the relation of subject and object and the relation of material and ideal in the process of activity. The relation of the matter and consciousness is indeed more abstract than the relation of the subject and the object but from the world-view it is still more fundamental. In this process, the transformation of material and ideal and vice versa is realised. The change of material into ideal must be in the influential phases practical.

From the reciprocal influence of subject and object in the activity we can emerge these basic theses:

1. Object determines the activity of the subject and at the same time affects the subject. Quality, structure and laws of object are important for the network of notions, methods, place of action and goals of the subject. The affect of the object on the subject is valid only when the object is inherent in the field of action of the subject. Contained knowledge of the object by the subject assumes the possibility of influence of the object on the subject by the means of a practical action. From this follows that activity without the relation to object does not exist.

2. Subject is relatively individual resource of action. It does not always react directly and linearly to the external influence of the object by the means of its knowledge, skills, experience or visualisation of the aim. Its activity is the result of a complicated "process of breakage".

3. In the human activity or with its help, the needs and interests of the subject are objectified in material or ideal results which were anticipated in the aim and are reflected in the shape of the object. All the moments of the activity must be understood as a process of transfer from objective to subjective or vice-versa.

When creating a cognitive reflection, the subject starts to subordinate the object to its own subjective aims. For each activity the idealistic reasons of action, such as motives and interests have an influential importance.

\section{References:}

[1] FUCHSOVÁ, K., KRAVČAKOVÁ, G.: Management of working motivation (in Slovak), Bratislava: IRIS, 2004, p. 170, ISBN 8089018-66-1

[2] BLAŠKOVÁ, M.: Management of human sources (in Slovak), Žilinská univerzita, Žilina, 1998, p. 162, ISBN 80-71000-549-5

[3] LEONTIEV, A. N.: Activity Consciousness Personality (in Slovak), Bratislava, VEDA, 1979, p. 180

[4] KUZMIN, J. S., SVENCICKIJ, A. L.: Social Psychology in a company (in Slovak), Bratislava, ROH, 1985, p. 195

[5] USNADZE, D. N.: Experimental curriculum of psychological approaches (in Russian), Tbilisi, 1958

[6] VÁROSS, M.: Introduction to Axiology (in Slovak), Bratislava, Epocha, 1970, p. 354

[7] NAKONEČNÝ, M.: Social Psychology (in Czech), Praha, Academia, 1999, p. 287, ISBN 80-200-0690-7

[8] VÝROST, J., SLAMĚNÍK, I.: Applied Social Psychology I. (in Czech), Praha, Portál, 1998, p. 369, ISBN 80-7178-269-6.

[9] BOROŠ, J.: Motivation and Human Emotionality. (in Slovak), Bratislava, ODKAZ, 1995, p. 180, ISBN 80-85193-42-6

[10] DŽUKA, J.: Motivation and Human Emotions. (in Slovak), Prešov: Prešovská univerzita v Prešove, 2003, p. 156, ISBN 80-8068-1694. e-kniha: http://www.pulib.sk/elpub/FF/Dzuka1/index.htm

[11] NÁKONEČNÝ, M.: Motivation and Human Behaviour. (in Czech), Praha: Academia, 1997, dotlač 2004, p. 270, ISBN 80-200-0592-7 